\title{
POLÍTICA DEL ARTE Y ARTE POLÍTICO: SOBRE CRÍTICA DEL PODER Y AUTONOMÍA ESTÉTICA
}

\section{Carlos Martínez Gorriarán}

Universidad del País Vasco / Euskal Herriko Unibertsitatea. Dpto. Filosofía de los Valores y Antropología Social

\section{Resumen}

La conversión del arte en plataforma ideológica puede ser una moda que sacrifique la autonomía del arte a nuevas formas de heteronomía sin sentido. De ese modo la crítica y la resistencia se convierten en retórica y dependencia, como la integración del arte más rebelde en los grandes centros y eventos al servicio de la industria cultural y del turismo, y en el coleccionismo especulativo. La rebeldía estética se ha convertido en muchos casos en una impostura perfectamente integrada en la sociedad del espectáculo, incluyendo un arte kitsch que parodia la transgresión creativa. En este artículo revisaré algunos ejemplos de las dos actitudes más antagónicas: la conversión del arte en activismo político con Joseph Beuys, el body-art, y Ai Weiwei y el arte chino actual; en el polo contrario, la transgresión integrada de Jeff Koons, Damien Hirst y la firma comercial Benetton.

Palabras clave: ARTE POLÍTICO; ARTE FEMINISTA; BEUYS, JOSEPH (1921-1986); CHINA; SOCIEDAD DEL ESPECTÁCULO

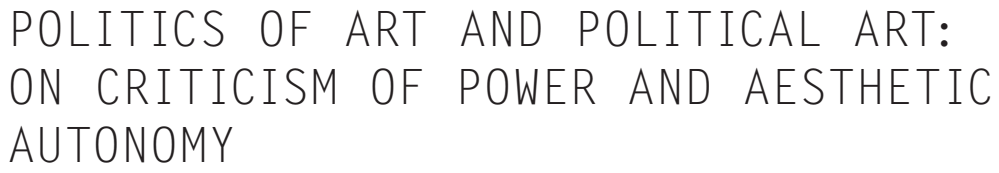

Abstract

The conversion of art into an ideological platform can be a fad that sacrifices the autonomy of art to new forms of meaningless heteronomy. In this way, criticism and resistance become rhetoric and dependence, such as the integration of the most rebellious art in the great centers and events at the service of the cultural industry and tourism, and in speculative collecting. The aesthetic rebellion has become in many cases an imposture perfectly integrated into the society of the show, including a kitsch art that parodies the creative transgression. In this article I will review some examples of the two most antagonistic attitudes: the conversion of art into political activism with Joseph Beuys, body-art, and Ai Weiwei and current Chinese art; in the opposite pole, the integrated transgression of Jeff Koons, Damien Hirst and the commercial firm Benetton.

Keywords: POLITICAL ART; FEMINIST ART; BEUYS, JOSEPH (1921-1986);; CHINA; SHOW BUSINESS

Martínez Gorriarán, Carlos. 2018. "Política del arte y arte político:

Sobre crítica del poder y autonomía estética“. AusArt 6 (2): 61-77. DOI:10.1387/ausart.20264

\section{AUSART}




\section{LA DIMENSIÓN POLÍTICA DEL ARTE Y SU PAPEL EN LA CRÍTICA SOCIAL}

Una peculiaridad del arte y de las experiencias estéticas que produce es su carácter doble: son únicas en tanto que prácticas y vivencias personales, pero también conforman la institución social que la modernidad denominó 'arte' y hoy incluye una densa red de agentes que incluye artistas, comisarios, mercado, coleccionistas, crítica, teóricos, público, museos, ferias, escuelas y publicaciones. Su doble naturaleza dota al arte de la capacidad de generar experiencias únicas con una potente dimensión social, relacionada con los valores culturales y con las demás instituciones políticas y sociales. Por tanto, el arte cumple sin contradicción funciones tanto privadas como públicas, pluralidad que autoriza sin duda alguna a hablar no sólo del papel político del arte, sino de formas de arte decididamente políticas en todo un abanico de sentidos, desde legitimar el orden instituido al intento de subvertirlo.

Esto no implica que los papeles privados y públicos interactúen con armonía, ni que siempre sean los mismos y para todo el mundo. A lo largo de la historia encontramos complejos procesos de pérdida y reconstrucción de sentido estético. Por ejemplo, la tragedia clásica griega jugó un papel político primordial en la vida social de la polis, especialmente en las democráticas pero, una vez desaparecida esa forma política a mediados del siglo IV a.e., las tragedias pasaron a convertirse en un espectáculo, el teatro, destinado al ocio y carente del papel político originario; posteriormente fueron un modelo de texto griego clásico; más tarde aún, una fuente de problemas intemporales que inspiraron a Hegel, Nietzsche, Freud y otros teóricos; finalmente, un modelo dramático reinterpretado según valores modernos. Las obras de Esquilo, Sófocles y Eurípides se han transmitido hasta hoy con esta 'devaluación' o despolitización, podríamos decir, que ha cambiado su sentido original.

La doble función público-privada inmanente del arte experimenta una gran tensión en la modernidad, entre los polos del esteticismo centrado en la autonomía absoluta o 'arte por el arte', y el arte comprometido en causas políticas. Las vanguardias del siglo XX muestran que esa tensión también es una fuente de energía creativa. En la era posmoderna los valores estéticos incrementan su importancia debido a la enorme influencia de la comunicación y la industria cultural. En este punto, la conversión de los objetos estéticos en productos de tráfico mercantil y consumo masivo han conducido al arte a una situación paradójica: la función crítica del arte es por una parte más citada y reclamada que nunca, hasta ser la única justificación de la actividad creativa para no 
pocos autores, pero por otra parte aparece completamente integrada en la red de relaciones económicas, políticas y comunicacionales que, según afirma la crítica, el arte aspira a mostrar, superar y transgredir desde fuera, es decir, sin integración.

La pregunta no es si el arte desempeña una función política, pues es evidente que sí, sino en qué puede consistir hoy esa función desde un punto de vista crítico. La facilidad de la cultura actual o 'sociedad del espectáculo' (Debord 1967) para integrar, explotar y banalizar incluso las críticas estéticas más transgresoras provoca respuestas muy diferentes, por ejemplo la nihilista de la renuncia o destrucción del arte (dadaísmo), el intento de fundir arte y vida o artey activismo político (vanguardismo), y la tergiversación de la transgresión estética para producir más objetos destinados al consumo masivo de la industria cultural. En este artículo revisaré ejemplos de las actitudes más antagónicas: la conversión del arte en activismo político con Joseph Beuys a partir de prácticas dadaístas (Duchamp), el body-art y arte feminista de Ana Mendieta y otras mujeres, y el trabajo político de Ai Weiwei y otros artistas chinos; en el polo contrario, la transgresión integrada de Jeff Koons, Damien Hirst y la firma comercial Benetton.

El valor y sentido de la crítica estética aparecen vinculados a la cuestión de la autonomía del arte, es decir, a su libertad respecto a reglas externas o no estéticas, de tipo moral, ideológico, científico o religioso, por ejemplo. En la modernidad, el debate sobre la autonomía estética y su sentido surge de modo explícito en la Ilustración y culmina con el romanticismo. A partir de Kant (la capacidad de juzgar) y Hume (la crítica del gusto) se formularon tesis muy distintas sobre el problema, pero con el romanticismo la autonomía acabó configurada, a pesar de la crítica de Hegel, como el predicado fundamental del verdadero arte: aquel cuyo valor no depende de ideas preconcebidas ni de convenciones sociales, sino de la experiencia subjetiva y -también o- de la transformación social que pueda motivar o producir. Este nuevo valor hizo del arte una práctica a contracorriente, incluso cuando el artista era de mentalidad conservadora en otros ámbitos (caso de Manet y otros impresionistas).

En este marco conceptual el arte puede ser crítico mientras tenga autonomía, es decir, mientras la ejerza, no porque tenga cierta ideología. Si fuera asunto de ideología el "realismo socialista", pongamos por caso, sería arte revolucionario, cosa que obviamente no fue. La paradoja surge cuando el arte renuncia a la autonomía en nombre de su misión crítica y elige reducirse al activismo político o a la reflexión teórica. Es el trayecto que ya hicieron el constructi- 
vismo ruso revolucionario (y en general las corrientes del arte concebido como 'fábrica del hombre nuevo'), y en tiempos recientes movimientos como, por ejemplo, el arte conceptual disuelto en cierta 'filosofía analítica del lenguaje'.

\section{DE SCHILLER A BEUYS PASANDO POR DUCHAMP: LA TENSIÓN PÚBLICA-PRIVADA EN LA EXPERIENCIA ESTÉTICA}

Los creadores románticos, y muy en particular los poetas-filósofos alemanes como Friedrich Schiller, soportaron un régimen que reprimía su libertad de crear. Así pues se enfrentaron al dilema de optar por un arte transformador, en sintonía con cambios políticos como la revolución francesa, o explorar líneas intimistas sin compromisos políticos. Como muchos otros contemporáneos, inicialmente Schiller apoyó la revolución francesa. Incluso fue nombrado Ciudadano de Honor de la República en homenaje al impacto revolucionario de sus obras dramáticas, algunas de ellas prohibidas en los estados alemanes, pero acabó rechazándola tras la ejecución de Luis XVI y la deriva al terror jacobino.

Schiller dio un giro al dilema entre arte comprometido o personal planteándolo como contradicción o antinomia entre la 'gracia' (creatividad) y la 'dignidad' (libertad), trasuntos del principio estético y ético que a menudo aparecen confrontados de modo negativo. La solución schilleriana propone una síntesis donde la dignidad del individuo, su libertad, no es sacrificada por el poder político ni la convención social, pero tampoco autoriza a la gracia o creatividad sacrificarse a la acción política. La gracia vive en el cultivo contemplativo del sentimiento de belleza, una capacidad universal y a la vez radicalmente individual donde todos somos iguales y libres, ya que no puede ser limitada ni prohibida por agentes externos a uno mismo.

Kant, la fuente de Schiller, había planteado el problema de un modo muy diferente, pues en su filosofía la libertad es la conformidad racional entre la ética o ley moral y la voluntad. Las Cartas sobre la educación estética del hombre (1793-1794) de Schiller llevan a una conclusión radicalmente diferente, pues la libertad es la experiencia estética: "Solo la belleza hace feliz a todo el mundo, y todo ser olvida sus limitaciones tan pronto experimenta los encantos de lo bello" ([1794] 1981, 163). Ahora bien, la belleza sólo puede ser una experien- 
cia individual o vivencia, pues aunque pertenecemos a la misma especie y a una sociedad dada, "no podemos hacer común nuestro individuo" (162); por tanto, "En el estado estético cada uno es (incluso el instrumento servil) un ciudadano libre, con los mismos derechos que el más noble, y el entendimiento, que somete poderosamente a sus fines a la masa pasiva, tiene que inquirir su determinación. Aquí, pues, en el reino de la apariencia estética, se cumple el ideal de la igualdad, ideal que de tan buena gana quisiera ver realizado el entusiasta, incluso en el dominio de los hechos". Las vivencias de la belleza, donde nadie es más que nadie, abren las puertas a la auténtica igualdad, a una sociedad reconciliada por el "estado de la apariencia bella". Y tal estado se halla en "la propia naturaleza bella, donde el hombre camina a través de las relaciones más complicadas con atrevida sencillez y tranquila inocencia, y donde no tiene necesidad de menoscabar la libertad extraña para afirmar la suya, ni de sacrificar su dignidad para manifestar su gracia" (Schiller [1794] 1981, 164-5).

En rápida síntesis, Schiller justifica un programa de retirada del mundo en beneficio de la experiencia estética interior donde crece la genuina libertad, pero su teoría también alberga la idea matriz de un mundo estético radicalmente libre e igualitario. Así pues, se puede leer a Schiller como una advertencia contra el activismo político, pero también como una radical fundamentación estética de la política. Una contradicción que no deja de ser profundamente estética. No es extraño que Josep Beuys, paradigma del artista-activista contemporáneo, pidiera prestar nueva atención a Schiller.

Entre tanto, la evolución del arte siguió por otros derroteros. Uno de los más visitados desde principios del siglo XX fue el inaugurado por Marcel Duchamp y su práctica, más que idea, del antiarte como experiencia más subjetiva que política, conectando con la tesis de Schiller. Duchamp era profundamente antipolítico, más que apolítico, pero su cultivo de la transgresión provocadora, su talento histriónico, su idea de que el verdadero arte, si existe, es sólo cierta forma de vivir y su hostilidad a las convenciones le convirtió casi inevitablemente en el gurú delas generaciones posteriores de artistas políticos. Sin embargo, él siempre insistió en que su obra carecía de propósito ideológico: "No considero que el trabajo que he realizado pueda tener en el futuro ninguna importancia desde el punto de vista social. Así pues, si usted quiere, mi arte consistiría en vivir" ([1967] 1972, 114).

El pensamiento estético de Duchamp está absolutamente orientado a la experiencia como tal, o vivencia, y cuanto más disruptiva mejor, rechazando el 
lado del arte como institución cultural: "Somos nosotros quienes hemos dado el nombre de 'arte' a las cosas religiosas; entre los primitivos, esa palabra ni siquiera existía. Lo hemos hecho pensando en nosotros, en nuestra propia satisfacción. Hemos creado esa palabra para nuestro exclusivo y privativo uso: es algo que se parece mucho a la masturbación. No creo mucho en el aspecto esencial del arte. Podría crearse una sociedad que rechazara el arte, los rusos estuvieron a punto de hacerlo. Pero, por otra parte, no es algo divertido, pero es algo que debe considerarse" ([1967] 1972, 163)1.

Paradójicamente, Duchamp empleaba el arte como medida de calidad de la acción, por ejemplo para negarla al activismo político: "No comprendo en absoluto la política y constato que es realmente una actividad estúpida que no conduce a nada. Tanto si eso conduce al comunismo, a la monarquía, o a una república democrática, para mí es lo mismo. Usted me dirá que los hombres están obligados a hacer política para vivir en sociedad, pero eso no justifica en absoluto la idea de la política como un gran arte" ([1967] 1972, 169)2.

Podría considerarse a Beuys el heredero de Duchamp a través del neodadaísmo de Fluxus. Lo fue en este sentido, pero su interpretación del maestro francés del antiarte aparece llena de reservas derivadas, como es natural, del desprecio de aquél por cualquier compromiso político e institución social, que para Beuys eran la razón de ser del arte. Su obra intentó la fusión de arte, acción y discurso traspasando límites performativos, de modo que el arte fuera un tipo de acción integral capaz de revelar un discurso activista, mostrado en el acontecimiento. Al contrario que Duchamp, no trató de desacralizar el arte y ofrecerlo como una forma de diversión, sino como una manera trascendente de encarar la vida. La vía de Duchamp conduce a una especie de esteticismo negativo y egocéntrico en el fondo muy 'burgués', según Beuys ([1985] 2006, 181).

El concepto de 'arte expandido' de Beuys promovía una nueva cultura y un nuevo papel para el arte a partir de la premisa de que "todo hombre es artista", pero preservaba la autonomía del arte como acontecimiento irreductible a la mera instrumentación. En realidad, el papel del arte es mantener su autonomía para, mediante su expansión más allá de la obra, trasladarla al campo de la política y la economía. El suyo es un arte profundamente carismático y terapéutico (también ha sido llamado 'chamánico') arraigado en la consciencia misma, rasgo compartido por muchos artistas visionarios (por ejemplo, Johannes Itten y Jorge Oteiza). En una entrevista de 1979 Beuys definía así su proyecto y concepto de misión del arte: "Sí, quizá tenga una misión... Cam- 
biar el orden social. Ante todo cambiar el sistema del dinero, eso es lo más importante de todo, cambiar el sistema del dinero. El dinero y el Estado son los únicos poderes represivos en el presente. El dinero, el Estado y la [interacción] entre ambas realidades. No existirá otro poder mientras que la gente vaya a votar y diga sí, sí y sí a este sistema, es decir, mientras este sistema sobreviva. Por eso hemos de emprender radicalmente otro camino y quitar esto de en medio. Radicalmente" ([1985] 2006, 111).

Como tantos revolucionarios, Beuys enfrentó la contradicción de cambiar el sistema desde dentro del sistema, descubriendo que la única forma constructiva de cambio es la acción política. Pero ésta necesita dinero y publicidad, y para obtenerlo Beuys siguió produciendo objetos de arte que vender al mercado para financiar sus numerosas campañas, compromiso que en cierto modo comprometía su ideal anarquista del mundo sin dinero. Beuys solventaba la contradicción afirmando la autonomía del arte al margen de las manipulaciones mercantilistas o de otra índole que pueda sufrir. Por ejemplo: "Si un cuadro de Rembrandt está colgado de una pared, es indiferente en qué pared esté colgado, sea la de un burgués o la de un museo. Si, por otra parte se encontrara en un almacén, no perdería su valor de obra de arte, conservaría su función absoluta. (...) se trata simplemente de una sustancia que se transvasa en el tiempo, algo así también ha cambiado el desarrollo de la consciencia del hombre" ([1985] 2006, 183).

Pocas de las iniciativas estético-políticas impulsadas por Beuys han sobrevivido, excepto el partido Bündnis 90 / Die Grünen (Alianza 90/ Los Verdes), pero su concepción de la crítica social mediante acciones y experiencias estéticas, o 'arte expandido', amplió profundamente nuestra comprensión de los límites y sentido del arte.

\section{ACTIVISMO POLÍTICO I: LA POLÍTICA DEL ARTE Y EL ARTE CHINO ACTUAL}

En los años 60 dos países occidentales muy diferentes a la sazón se esmeraron con éxito en utilizar la capacidad crítica del arte moderno para fines políticos plenamente instrumentales: España y Estados Unidos. En España, la dictadura franquista aprovechó la espectacular emergencia de nuevos talentos en los años 50 y 60 (Millares, Saura, Tàpies, Oteiza, Chillida...) para una exitosa 
diplomacia cultural (Gabriel Ureña 1982) con el mensaje de que el régimen no era totalitario porque concedía a los artistas plena libertad de crear con apoyo oficial... mientras no se metieran en política. En la Guerra Fría, Estados Unidos inició una política cultural de altos vuelos centrada en el arte, presentando al expresionismo abstracto (Pollock, de Kooning, Mothersen, Kline...) como la primera vanguardia puramente americana, pronto seguida por el pop-art. En contraste con la esclerosis del arte oficial de los países socialistas, estos movimientos parecían hacer de Estados Unidos la punta de lanza mundial de la libertad de creación y de la democracia. A la luz de estos precedentes no debe sorprender que un signo inequívoco de la transformación de China tras liquidar la Revolución Cultural fuera la tolerancia gubernamental de un arte avanzado relativamente libre -ciertamente, llena de contradicciones-, últimamente convertida en "una estrategia del poder para encumbrar China a un estatus global." (Fernández del Campo \& Sanz 2011, 85)

Como la España de Franco, China sigue siendo una férrea dictadura política con libertad económica, y la libertad creativa llega hasta los límites represivos, más o menos arbitrarios, que impone el gobierno: están excluidas las críticas explícitas de la dictadura y sus violaciones de los derechos humanos. Tras la rebelión estudiantil y las masacres de 1989, el mundo intelectual fue el objetivo de una represión brutal que encarceló y mandó al exilio a muchos artistas. En consecuencia, China es hoy el último gran país donde la dialéctica de oposición arte-política prolonga la era de las vanguardias insumisas. El compromiso político del arte está centrado en el rechazo de la dictadura y la exigencia de plenas libertades, aunque con formas plenamente sintonizadas con las corrientes cosmopolitas.

Por otra parte, el compromiso político-estético chino no es cosa nueva. Se remonta al menos a la prolongada crisis del siglo XIX y a la ambivalente actitud de las élites intelectuales ante la cultura occidental, oscilando entre el rechazo a la injerencia imperialista y el atractivo de las posibilidades del nuevo arte para la renovación del propio; los artistas excéntricos y sus conflictos con el poder político y la autoridad también son una tradición china multisecular (Fernández del Campo \& Sanz, 2011). Esa tradición ayudó en la rapidísima transformación del arte chino en los años 80. El Grupo 85 New Wage y otros abrieron debates sobre el sentido del arte actual con obras tan chinas como internacionales. En ciertos aspectos se repitió el guion evolutivo europeo, con influyentes neo dadaístas muy interesados en Duchamp y Beuys, como Huang Yongping, del grupo Xiamen Dada. Tras la revuelta estudiantil y la masacre de la plaza de Tian'anmen en 1989, su trabajo fue prohibido y se refugió en París. El exilio 
fue el destino inevitable de muchos de estos artistas cuando el gobierno comunista les culpó de alterar el orden y promover la rebelión democrática con sus obras, todo un homenaje a la potencia política del arte.

Ai Weiwei es uno de los artistas más característicos del compromiso político del arte chino contemporáneo; en su caso, hasta convertir el activismo internacional por los derechos humanos, por ejemplo sobre la tragedia de las emigraciones irregulares a través del Mediterráneo, en eje de su trabajo actual. En el marco de la acción Cuento de Hadas celebrada en 2007 en la Documenta Kassel, Ai llevó a 1001 ciudadanos chinos que nunca habían salido del país para que asistieran a los eventos y se mezclaran con el público, ejemplo de su trabajo para que la cultura global entrara en China y se mezclara con la propia. Pero conseguirlo exige cambios políticos remotos por el momento, convirtiendo la lucha por la libertad en requisito para la creación estética. En una entrevista en Kassel, Daniel Birnbaum le preguntó: "¿Qué les recomendaría en la actualidad a los artistas jóvenes chinos?". La respuesta de Ai fue: "Luchad por la libertad, olvidaos del arte" (Munroe, Tinari \& Hanru 2018, 274).

Sin embargo, no es una llamada dogmática a renunciar al arte para pasar a las barricadas políticas; Ai Weiwei tiene un pensamiento complejo y su libertad de espíritu produce fértiles paradojas. Lo que propone, partiendo de la insuficiencia del arte para alumbrar por sí mismo un nuevo mundo, es emplear la autonomía estética para potenciar un pensamiento socio-político no sólo crítico, sino más innovador y creativo. En una entrevista reciente del diario Le Figaro (2018), declaraba: "L'art contemporain tout seul ne suffit pas d'un point de vue critique, comme d'un point de vue socio-politique. II faut une ligne, un contexte, une confrontation. Le travail des artistes est de poser des questions, de remettre ainsi marche notre compréhension du monde, de l'esthétique, de susciter nos émotions pour repenser nos idées politiques et sociales. L'esthétique a un lien direct et fort avec la philosophie et la morale"3.

China padeció durante décadas la dictadura estética del realismo socialista, con una pobreza intelectual y un aislamiento del mundo difíciles de concebir hoy. Desde el principio del fin de la Revolución Cultural resultó evidente que más libertad y mejor arte eran dos fuerzas en retroalimentación de un solo proceso de cambio. Artistas como Cai Guo-Qiang (2016) han experimentado una rápida evolución personal que repite la historia del arte contemporáneo, del neoimpresionismo a nuevos medios y formas. El arte chino entró de modo casi automático, si se quiere, en el conflicto con su propia autonomía. El compromiso político plantea con renovada claridad la tensión entre ésta y las misiones 
sociales y políticas. Propiedades estéticas como la autoreferencialidad y la polisemia acaban siendo obvios obstáculos para tales desempeños, salvo si adoptan mensajes reduccionistas que pueden reducirlo a propaganda. Es un caso frecuente. En la España franquista, la dictadura no puso objeciones a la obra 'abstracta' de los artistas comunistas de Equipo 57 (Ángel Duarte, José Duarte, Juan Serrano y Agustín Ibarrola), pero censuró y reprimió la propaganda política "realista" que los mismos artistas hacían en Estampa Popular; una era políticamente ininteligible y la otra muy explícita. Del mismo modo, Eduardo Arroyo tuvo que exiliarse por el corrosivo contenido político de su realismo pop (no menos corrosivo con gurús como Duchamp). En China, los mensajes explícitos de Ai Weiwei contra la dictadura del partido único han sido objeto de ejercicios ejemplares de brutalidad represiva, desde el encarcelamiento y la prohibición de viajar hasta la destrucción por sorpresa de su estudio en Pekín este mismo año, obligando al artista al exilio.

\section{ACTIVISMO POLÍTICO II: EL BODY-ART DE LOS SESENTA Y EL ARTE FEMINISTA}

Traspasar los límites heredados del arte como institución social mediante transgresión, experimento, investigación, proyecto o como queramos llamarlo, entendiéndolo como una misión política intencional, es no sólo perfectamente viable, sino un salto posible gracias a la autonomía de la creación estética. Un buen ejemplo es el body-art de la década de los sesenta y setenta y el papel protagonista de muchas mujeres en ese campo, hasta configurar el arte de género feminista. Ciertamente, algunas mujeres ya tuvieron un papel importante en el impresionismo, más aún en las vanguardias históricas, y mucho más del reconocido al principio en el expresionismo abstracto americano (tanto artistas como galeristas y promotoras). Pero las neovanguardias de la posguerra fueron mucho más allá, planteando problemas directamente vinculados al movimiento feminista. Importa que ese arte emergente no surja tanto, o sólo, de la crítica al estilo de la influyente obra de Simone de Beauvoir, sino más bien de un nuevo desarrollo de la autonomía del arte donde la perspectiva, la experiencia y la sensibilidad de las mujeres en cuanto tales desempeñaron el papel capital.

La obra de Ana Mendieta es paradigmática a este respecto. Mendieta estaba convencida de la importancia social del arte, de su necesario compromiso con 
una cultura no conformista, y de la necesidad de fijar el foco de su obra en la opresión y discriminación de minorías y mujeres, en la violencia sexual que éstas padecen, en sus dificultades para crear una imagen autónoma y en otros asuntos poco o nada transitados hasta entonces. Pero el arte de Mendieta no es retórico y no se limitó a un discurso feminista o multicultural. Desarrolló su propio campo de representación a base de earthwork efímero, acciones y fotografía, entretejiendo una profunda y creativa polisemia. Produjo un universo formal no menos expandido que el de Beuys, y es en ese campo fuertemente original y denso, biográfico y público, donde sus ideas acerca de la política y los cambios sociales cobran su dimensión estética.

Podríamos decir lo mismo de Marina Abramovic o de Cindy Sherman, entre otras muchas. Son artistas que han logrado un arte simultáneamente universal, comprometido políticamente y con una fuerte presencia de la autobiografía, real o ficticia; su universo de representaciones mantiene íntegra su autonomía y el discurso tiene un papel subordinado. El texto que Ana Mendieta leyó en 1982 en el New Museum of Contemporany Art de Nueva York lo deja claro:

"Creo que todos sabemos que hay dos culturas dentro de esta cultura. Una es la cultura de la clase dominante, de la clase reaccionaria, que paraliza todo avance social del hombre esforzándose para que toda la sociedad se identifique con ella y sirva a sus intereses. Banalizan, mezclan, distorsionan y simplifican la vida. No hay ningún uso puro o real. Lo llaman estilización. Crean un producto, un estilo que domina los medios de comunicación, y ahora también las artes en todas sus manifestaciones. (...) para mí el arte es una cuestión de vocación, y eso debe sonar ridículo a los burgueses. El riego que corre la verdadera cultura hoy es que si las instituciones culturales están gobernadas por personas que forman parte de la clase dominante, el arte puede volverse invisible, porque se negarán a asimilarlo.Creo que el hecho de que estéis hoy aquí es una prueba de que existe otra cultura al margen de la cultura de la clase dominante. Por supuesto, lo que me aportan los grandes trabajos artísticos no sólo tiene que ver con mi experiencia, sino el propio hecho de que se crearan y de que existan. Ahora estoy segura de que muchos de ellos se crearon en condiciones tan adversas como las que atravesamos hoy. Y eso prueba que sobreviviremos. Por eso vuelve una y otra vez la cuestión de la integridad en la estética de manera histórica. Es una cuestión personal que afronta cada artista. Es una lucha constante. Están viniendo tiempos difíciles, pero creo que los artistas seguiremos haciendo nuestro trabajo. Seremos ignorados pero estaremos ahí. Gracias". 
El arte feminista también surge de la confrontación con el papel subordinado de las mujeres en los movimientos vanguardistas, como la supeditación de Lee Krasner a su cónyuge Jackson Pollock. Utilizar su propio cuerpo desnudo como obra de arte en diferentes tipos de acciones transgresoras de gran impacto emocional servía, según Carolee Schneeman, para transgredir las "líneas territoriales y psíquicas de poder por las que las mujeres eran admitidas en el Club Artístico de los Sementales" (Citado en Jones 2006, 61). Se trataba de expandir el concepto y práctica del arte y no sólo de admitir a las mujeres en el arte consolidado. En ese sentido integral es mucho más que 'arte feminista', del mismo modo en que el barroco es mucho más que cierto 'arte cristiano'.

Su emersión no puede separarse de la revolución sexual y moral de los sesenta, con el auge del feminismo, la tolerancia y educación sexual y la progresiva admisión de la homosexualidad, ni de la lucha por los derechos civiles de las minorías segregadas, especialmente en Estados Unidos. Cambios que, pese a la retórica revolucionaria dominante entre los teóricos, eran de un signo evidente liberal, más centrado en la emancipación de los sujetos sometidos que un 'cambio de sistema' al estilo de Beuys. Las interpretaciones teóricas de este arte usan y abusan de marcos posmarxistas, posestructuralistas, deconstructivistas y lacanianos, pero el hecho es que los cambios de conducta moral y el progresivo incremento de la tolerancia en las sociedades occidentales más secularizadas, después más o menos adoptadas por el resto del mundo, tuvo mucho más que ver con la eclosión y aceptación de las transgresiones estéticas que con la inspiración de Lacan, Foucault y Derrida.

Contra lo que sostiene la perspectiva antiliberal, la irrupción del nuevo arte feminista no parece una consecuencia de la hipermercantilización del cuerpo por la histeria consumista. La alienación corporal fue infinitamente peor en la sociedad victoriana y bajo la primera revolución industrial, por no hablar de los millones de seres asesinados en los Estados totalitarios y en las guerras mundiales y genocidios, entonces muy recientes. Es inmoral acusar al consumismo del capitalismo desarrollado de alienar más los cuerpos que los campos de exterminio totalitarios o el hambre y la enfermedad en los países más pobres. Lo que ocurrió fue otra cosa, y ahí brilló la capacidad transformadora del arte autónomo y su valor para la crítica constructiva. El nuevo arte político feminista formó parte de un proceso acelerado de cambio cultural facilitado por la derrota de nazis, fascistas e imperialistas japoneses, por el nuevo papel de las mujeres durante la guerra y posguerra, por la extensión del sufragio femenino, el trabajo y la educación, por el auge de la secularización de las 
creencias, y por los veloces cambios que abrieron una reflexión activa sin precedentes sobre la mujer en cuanto sujeto social y sexual autónomo, y no mera compañera o pariente de hombres varones.

Muchas explicaciones teóricas de corte posmarxistas y posestructuralistas adoptan, al parecer sin darse cuenta, el dualismo religioso o cartesiano de los seres humanos como compuestos de un cuerpo y un alma o mente. Y precisamente la crítica de ese dualismo a través de la reivindicación de la sexualidad reprimida y de la confrontación con la violencia sexual es uno de los ejercicios más fértiles del arte feminista. El énfasis de aire psicoanalítico en considerar que el 'yo' es el cuerpo domesticado por la cultura represiva parece un modo represivo de ignorar la autonomía del arte del cuerpo, que busca satisfacer más impulsos legítimos que la denuncia social. Por ejemplo, la teoría de Amelia Jones $(2006,36)$ explica la emergencia del nuevo arte y el papel de las mujeres en el marco opresivo del pancapitalismo: "Este régimen pancapitalista consiste en una economía globalizada (una red gigantesca de intercambio comercial de objetos y cuerpos) que fuerza al individuo a entregarse a la redistribución dentro del molde pancapitalista del intercambio comercial para funcionar de una forma más eficiente". Al margen de que la explicación abusa de la tautología (el pancapitalismo es el pancapitalismo), resulta reduccionista identificar cuerpos (sujetos) y mercancías, porque priva al arte hecho con el cuerpo (del sujeto) de cualquier autonomía transformadora más allá del mero testimonio o ejemplo de esa red de intercambio en tanto que mercancía 'pancapitalista'.

Insistiendo en la conversión del cuerpo en obra y espectáculo, Ana Mendieta, Marina Abramovic o Cindy Sherman llevan al absurdo la violencia, la sumisión y las convenciones sexuales, colaborando a superar los dualismos antagónicos cuerpo-mente e individuo-sociedad que han basado mucha antropología filosófica. La sociedad pluralista de la posguerra estimuló el surgimiento tanto de la revolución sexual como el arte transgresor que atacó los tabúes y roles del conservadurismo preliberal. Pero, debido a la lógica evolutiva del arte (Martínez Gorriarán 2017), una vez producidas y admitidas como arte con todos los derechos, las formas transgresoras pasaron al estatus de arte integrado. 


\section{5. "ACTIVISMO" Y “TRANSGRESIÓN" COMO ESPECTÁCULOS DEL CONSUMISMO DE EMOCIONES}

Debemos a Guy Debord (1967) algunas de las mejores y más lúcidas anticipaciones del lugar del arte en la "sociedad del espectáculo", y en concreto sobre las dificultades a las que iba enfrentarse para realizar sus misiones políticas (en particular, la utopía de la fusión entre arte y vida). Para Debord eran invencibles, salvo en un eventual proceso revolucionario. Aunque él no limitó al arte su pronóstico apocalíptico, que pensaba válido para el conjunto de la sociedad, es en el dominio estético, y no en el político, donde sus aforismos resultan proféticos. Por ejemplo: "La realidad surge en el espectáculo, y el espectáculo es real" ([1967] 1998, 8); "El consumidor real se transforma en consumidor de ilusiones" (47); "la propia insatisfacción se ha convertido en mercancía desde el momento en que la abundancia económica se ha vuelto capaz de ampliar su producción hasta el tratamiento de esta materia prima" (59); "En esta época de museos, cuando ya no puede existir comunicación artística alguna, todos los monumentos del pasado del arte pueden admitirse en igualdad de condiciones" (189); "es un arte del cambio y, al mismo tiempo, la expresión más pura de la imposibilidad del cambio" (190).

La crisis del arte político surge cuando se acorrala a sí mismo negándose la autonomía que le permite crear algo nuevo, como hicieron en cambio las artistas de body-art vinculadas a la revolución sexual, a la multiculturalidad y al feminismo de los 60 y 70. Para hacer algo estéticamente interesante no bastan cierta metafísica de la rebeldía y voluntad de vanguardia, guiada por una ideología predeterminada. Esas actitudes conducen o bien a un arte ideológico, sin capacidad de transformar nada, o bien al consumo de kitsch emocional, que es un arte plenamente integrado disfrazado de revolución. La ideología es tan dañina para el arte como para la filosofía. Guy Debord acertó de nuevo a expresarlo con rara precisión: "El espectáculo es la ideología por excelencia, porque expone y manifiesta plenamente la esencia de todo sistema ideológico: empobrecimiento, servidumbre y negación de la vida real" ([1967] 1998, 215).

El entramado actual de instituciones culturales acredita una capacidad aparentemente ilimitada para integrar toda clase de transgresiones. Éstas han dejado de serlo cuando Transgresión se convierte en una asignatura más de una escuela de arte. Y nunca han existido tantas instituciones públicas y privadas consagradas a acoger, difundir y consagrar obras cuya intención es en 
muchos casos acabar conciertos valores y prácticas que esas instituciones encarnan, desde el mercado del arte a la gestión cultural. Cabe preguntarse si la identificación de arte y activismo político no ha conducido más bienal triunfo de la política convencional sobre el arte vocacional que reivindicaba Ana Mendieta.

*Un efecto de este proceso de absorción es el intento defensivo de blindar la obra con una retórica protectora de la banalización y de la interpretación caníbal, sin apreciar que nada banaliza más una obra que un manual de instrucciones de uso. Nada es más fácil de parodiar y expropiar que ese discurso moralizante que añade al kitsch formal el filosófico. En 1989, el año de la rebelión democrática china cuya brutal represión mandó al exilio o a la cárcel a centenares de artistas e intelectuales, Jeff Koons declaraba a Flash Art: "Hoy en día, la mayor prioridad de todo artista es enfrentarse a la crisis moral que amenaza con aplastarnos a todos. En mi opinión, los artistas deben utilizar todas las herramientas de que disponen, todas las que el denominado mundo real -la publicidad, y las industrias discográfica y cinematográfica- ha puesto a su alcance. Estos son nuestros competidores. Si el mundo del arte no utiliza los seductores medios que tenemos a nuestro alcance, será engullido por la publicidad y el mundo del espectáculo" (Jones 2006, 157) Lo que Koons hizo, obviamente, fue engullir al arte gracias a los circuitos de consumo de masas, explotando el aura de indignación moral que se espera nimbeal genuino vanguardista.

No es casual que Puppy, el megaperrito floral de Koons, una obra paródico-monumental, presida la entrada al Guggenheim de Bilbao, paradigma de esa puesta del arte al servicio de la industria cultural (turismo, servicios, publicidad, consumo de marcas). Koons ha conseguido que sus artefactos tengan la máxima cotización en el mercado del arte y sean sumamente populares. Su colección de monumentales postales pornográficas con su ex esposa y actriz porno Cicciolina trasladan al kitsch con buscada obscenidad las formas corporales heroico-intimistas del arte feminista de los setenta; para rematar la caricatura, Cicciolina tuvo una carrera política real de cinco años como diputada del Parlamento italiano, entreverada con sonoros escándalos legales por dinero con su ex marido y propuestas de empleo de la prostitución, equiparada con el amor, para educar a la juventud, eliminar el terrorismo y resolver conflictos bélicos.

Así que, en cierto modo, el proyecto vanguardista por excelencia, la disolución y fusión del arte con la vida, ha triunfado como parodia. El precio es convertir 
la transgresión en pose, moda o pura impostura. Así, la marca italiana de moda Benetton se hizo célebre -y muy criticada-por sus campañas de publicidad de sí misma (United Colors of Benetton)en las que el fotógrafo Oliviero Toscani parodiaba con gran eficacia, al servicio de intereses obviamente comerciales, estrategias autoreferenciales desarrolladas por artistas con propósitos anticonsumistas, por ejemplo los enigmáticos autorretratos de Cindy Sherman.

Otro artista del éxito, Damien Hirst, aprendió tan bien como Koons de la exitosa carrera mundana de Warholl y, sobre todo, descubrió el flanco de tergiversación que ofrecen las retóricas del arte político. Hirst ha logrado fama, títulos y una gran fortuna parodiando con sus obras de animales muertos suspendidos en formol, enteros o en trozos, algunas de las prácticas más violentas del arte más transgresor, el que expone la mortificación del propio cuerpo. También el sacrificio de animales y el embadurnamiento con vísceras, sangre y secreciones corporales de Hermann Nitsch y su Orgien Mysterien Teather como experiencia límite.

Una paradoja ilustrativa de la actual hegemonía de la caricatura transgresora y la indignación impostada es que la gran exposición sobre arte chino contemporáneo del Museo Guggenheim, Arte y China después de 1989, optara por prescindir en Nueva York de la obra estrella El teatro del mundo, de Huang Yong Ping, que subtitulaba al evento, debido a que la obra incluyeanimales vivos, en concreto insectos y reptiles, por temor al boicot de animalistas intransigentes con el empleo artístico de animales vivos enjaulados, por muy crítico con la dictadura china que pudiera ser el resultado. En cambio, Hirst puede -de momento- seguir amasando su fortuna exhibiendo como obras de arte animales muertos en porciones o enteros, pero en condiciones debidamente higiénicas y neutrales.

En la sociedad secularizada el arte ha sustituido a las religiones en la tarea de proporcionar emociones espirituales profundas y ejemplos de virtud, pero en la Iglesia del Arte, como en todas ellas, hay auténticos ascetas, místicos y mártires obligados a compartir su vocación con truhanes, hipócritas y la nutrida clerecía que vive de la institución.

\section{Referencias}

Beuys, Joseph. (1985) 2006. Ensayos y entrevistas. Ed. a cargo de Bernd Klüser; traducción, Miguel Salmerón. Madrid: Síntesis 
Cai, Guo-Qiang. 2016. My stories of paiting. Köln: Bonnenfantenmuseum

Debord, Guy (1967). 1999. La sociedad del espectáculo. Valencia: Pretextos

Duchamp, Marcel. (1967) 1972. Conversaciones con Marcel Duchamp. Por Pierre Cabanne; traducción de María Teresa Gallego Urrutia. Barcelona: Anagrama

Fernández del Campo, Eva \& Susana Sanz Giménez. 2011. Arte Chino Contemporáneo. San Sebastián: Nerea

Jones, Amelia. 2006. "Regresa al cuerpo, el lugar donde se manifiestan todas las escisiones de la cultura occidental". En El cuerpo del artista, ed. de Tracey Warr; traducido del inglés por Carme Franch Ribes. México DF: Phaidon

Martínez Gorriarán, Carlos. 2017. "La evolución peculiar del arte y la evolución cultural”. AusArt5 (2): 21-39

Mendieta, Ana. 1982. "Arte y política". Lumiere.net. Texto leído el 18 feb. en el New Museum of Contemporany Art, Nueva York. Traducido del inglés por Francisco Algarín Navarro. http:// elumiere.net/especiales/mendieta/mendietaarteypolitica.php

Munroe, Alexandra, Philip Tinari \& Hou Hanru. 2018. Arte y China después de 1989: El teatro del mundo. Catálogo de la exposición. Bilbao: Guggenheim Bilbao Museoa

Schiller, Johan Cristoph Friedrich. (1794). 1981. Cartas sobre la educación estética del hombre. Traducción del alemán y prólogo de Vicente Romano Garcia. Buenos Aires: Aguilar

Weiwei, Ai. 2018. "Je suis un alien de l'intérieur". Interview par Valérie Duponchelle, Le Figaro 15 sept. http://www.lefigaro.fr/arts-expositions/2018/09/15/03015-20180915ARTFIG00006ai-weiwei-je-suis-un-alien-de-I-interieur.php

\section{Notas}

${ }^{1}$ Merece la pena señalar que si bien Duchamp acertaba al subrayar el origen moderno occidental del concepto "arte", algo parecido pasa con el concepto "religión", de origen romano y más antiguo, pero no más "auténtico" ni primitivo. Los "primitivos" tampoco conocían la religión en nuestro sentido.

${ }^{2}$ No le debía ser tan indiferente a Duchamp el régimen político, puesto que en 1915 eligió refugiarse en Estados Unidos, y en 1955 adoptara la ciudadanía americana.

${ }^{3}$ «El arte contemporáneo no basta por sí solo para un punto de vista crítico, como punto de vista socio-político. Necesita una línea, un contexto, una confrontación. El trabajo de los artistas es hacer preguntas para rehacer nuestra comprensión del mundo, una estética, suscitar nuestras emociones para repensar nuestras ideas políticas y sociales. La estética tiene un vínculo fuerte y directo con la filosofía y la moral" (Ai Weiwei en Le Figaro, 15, 9, 2018). 